Piotr Klonowicz*, Jan Surwiło, Łukasz Witanowski, Tomasz K. Suchocki, Zbigniew Kozanecki, and Piotr Lampart

\title{
Design and numerical study of turbines operating with MDM as working fluid
}

DOI 10.1515/eng-2015-0050

Received March 18, 2015; accepted October 29, 2015

\begin{abstract}
Design processes and numerical simulations have been presented for a few cases of turbines designated to work in ORC systems. The chosen working fluid is MDM. The considered design configurations include single stage centripetal reaction and centrifugal impulse turbines as well as multistage axial turbines. The power outputs vary from about $75 \mathrm{~kW}$ to $1 \mathrm{MW}$. The flow in single stage turbines is supersonic and requires special design of blades. The internal efficiencies of these configurations exceed $80 \%$ which is considered high for these type of machines. The efficiency of axial turbines exceed $90 \%$. Possible turbine optimization directions have been also outlined in the work.
\end{abstract}

Keywords: ORC; turbines; MDM; numerical simulations; CHP

\section{Introduction}

\subsection{Motivation}

In the last few years the interest in alternative energy sources has been rapidly raising up. It is due to the increase of the environmental pollution and the threat of the global warming. Burning of the fossil fuels is believed to be the main cause of the greenhouse effect. The technology of Organic Rankine Cycles is a very promising one from the point of view of renewable energy sources. This paper describes the series of turboexpanders which are des-

\footnotetext{
^Corresponding Author: Piotr Klonowicz: The Szewalski Institute of Fluid-Flow Machinery of Polish Academy of Sciences, Fiszera 14 st., Gdańsk 80-231, Poland, E-mail: pklonowicz@gmail.com Jan Surwiło, Łukasz Witanowski, Tomasz K. Suchocki, Piotr Lampart: The Szewalski Institute of Fluid-Flow Machinery of Polish Academy of Sciences, Fiszera 14 st., Gdańsk 80-231, Poland Zbigniew Kozanecki: Technical University of Lodz, Institute of Turbomachinery, Wólczańska 219/223 st., 90-924 Łódź, Poland
}

ignated to operate in small-scale ORC CHP plants working with MDM as working fluid.

The presented turbines differ one from another with respect to the flow direction, number of stages, degree of reaction and power capacity which varies between $75 \mathrm{~kW}$ and $1 \mathrm{MW}$. The design process for each case begins with 1D computations which in some of the cases is followed by generation of the full stage geometry and numerical simulations.

\subsection{The MDM cycle}

Figure 1 shows the schematic of the multitask ORC test rig. It is being built in the laboratories of the Szewalski Institute of Fluid-Flow Machinery of Polish Academy of Sciences (IMP PAN). The maximum assumed pressure at the turbine inlet is $12 \operatorname{bar}(\mathrm{a})$ and the maximum temperature equals to $553 \mathrm{~K}$ (point 2). The back pressure is assumed to be 0.17 bar(a) (point 3). The system is powered by gas boiler which is connected with the MDM cycle by means of the thermal oil loops. The lower oil loop delivers the heat to the preheater and the upper one supplies the evaporator. The condensed working fluid is compressed by the feed pump. The heat received in the condenser can be used for heating purposes. The maximum power of the original system is $100 \mathrm{~kW}$ and it is assumed that it can be scaled up to $1 \mathrm{MW}$ depending on the various CHP applications.

\subsection{The set of turbine design parameters and turbine configurations}

Table 1 shows the set of turbine design parameters which correspond to different scales of the MDM cycle described above. It can be observed that the higher the design power output the more complex becomes the turbine configuration which is economically justified [1]. The turbine designed for $75 \mathrm{~kW}$ consists of an isolated centrifugal impulse stage while the radial turbines for $200 \mathrm{~kW}$ and $500 \mathrm{~kW}$ are single stage centripetal reaction machines. The axial turbines for $500 \mathrm{~kW}$ and $1000 \mathrm{~kW}$ have 10 stages with variable degree of reaction across the flow path. 
Table 1: The set of turbine configurations.

\begin{tabular}{|c|c|c|c|c|c|c|}
\hline Type & Power [kW] & $\begin{array}{l}\text { Inlet pres. } \\
{[\operatorname{bar}(a)]}\end{array}$ & Inlet temp. [K] & $\begin{array}{l}\text { Outlet pres. } \\
{[\text { bar(a)] }}\end{array}$ & $\begin{array}{l}\text { Rotational } \\
\text { speed [rpm] }\end{array}$ & $\begin{array}{l}\text { Number of } \\
\text { stages }\end{array}$ \\
\hline $\begin{array}{l}\text { Radial, im- } \\
\text { pulse }\end{array}$ & 75 & 7 & 521 & 0.17 & 20000 & 1 \\
\hline $\begin{array}{l}\text { Radial, reac- } \\
\text { tion }\end{array}$ & 200 & 12 & 553 & 0.17 & 13500 & 1 \\
\hline $\begin{array}{l}\text { Radial, reac- } \\
\text { tion }\end{array}$ & 500 & 12 & 553 & 0.17 & 8500 & 1 \\
\hline Axial & 500 & 12 & 553 & 0.17 & 3000 & 10 \\
\hline Axial & 1000 & 12 & 553 & 0.17 & 3000 & 10 \\
\hline
\end{tabular}

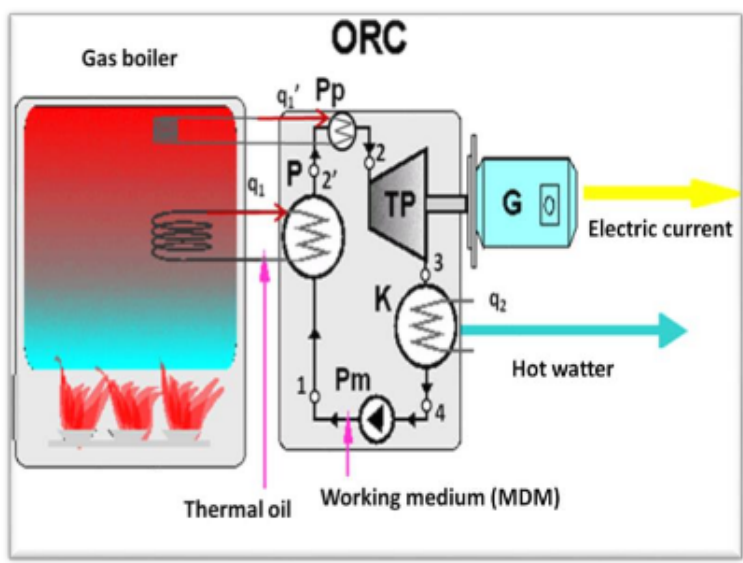

Figure 1: The schematic of the IMP PAN multitask ORC test rig.

\subsection{The design calculations}

The design calculations are based on the one-dimensional mean line code [2]. The loss calculations are based on the Craig-Cox loss model [3] which is one of the most comprehensive correlations. It is suitable for single stage and multistage axial turbines and the loss prediction error given by the authors did not exceed 1.25\%. However, it must be underlined that for radial turbines it may not be as precise because the forces act differently on fluid elements. What is more, MDM reveals a strong real gas behavior and it still remains an open question whether the classic correlations are reliable for these kinds of fluids. Recently, a lot of experimental effort has been made in order to investigate the dynamics of real gases [4-6].

\subsection{Geometry of the blades}

The full geometry of the blades was created for $75 \mathrm{~kW}$ and $200 \mathrm{~kW}$ turbines. As they consist of single and highly loaded stages, the flow in the nozzle is highly supersonic.
This flow regime requires a convergent-divergent channel design. There are various methods for designing this kind of geometry, however, a very efficient tool is the method of characteristics (MOC) for potential irrotational flow. The convergent-divergent nozzles designed for the presented turbine stages are flat and they produce parallel uniform flow [7]. In order to obtain the appropriate geometry the real gas behavior of the MDM was taken into account.

The rotor blade shapes were obtained by means of parametric geometry description based on Bezier curves created in Matlab environment and commercial software Ansys BladeGen [8].

\subsection{Numerical simulations}

The RANS simulations were performed by means of a commercial code Ansys CFX ${ }^{1}$. The numerical model used in the computations was similar to that used by other authors who simulated ORC turbine stages [9-12]. The equations describing the flow were solved by means of the finite volume method. Second order discretization scheme was applied. As the turbulence model the $k-\omega$ SST was selected. The thermodynamic properties of MDM were implemented via a property table generated in the Refprop library [13].

The imposed set of boundary conditions consisted of the total pressure and total temperature at the inlet, average static pressure at the outlet and the rotational speed of the rotor domain. The values of the boundary conditions corresponded to the design point. All of the computational meshes were hexahedral.

1 Ansys CFX, Release 12, 2009. 


\section{The $75 \mathrm{~kW}$ radial turbine}

One of the problems concerning pure radial stages is the centrifugal force that acts perpendicularly to the blades. However, due to the properties of the fluids with large molecules the enthalpy drops in turbines operating in Organic Rankine Cycles are relatively small.

The proposed supersonic, impulse and centrifugal stage is an atypical configuration and there is not many literature publications devoted to these kind of machines. Some research in this field was performed by Cho et al. [14] and Klonowicz and Brüggemann [10]. A clear advantage of these solution is a small axial thrust exerted on the shaft which is characteristic for the impulse stages in general. It is also relatively easy to manufacture the blades and apply the rotor shrouding as both the hub and shroud surfaces of the rotor are perpendicular to the axis of rotation. Additionally, the numerical simulations show a promising aerodynamic performance of this stage.

The design parameters are lower than in case of all the other cases described in this work. They were gathered in Table 2. The results of $1 \mathrm{D}$ computations are presented in Table 3 and Table 4, velocity triangles are shown in Figure 2.

The divergent part of the nozzle channel was designed by means of MOC as a flat nozzle producing parallel and uniform flow, Figure 3. For impulse and centrifugal turbine blade design no literature references has been found. The free vortex flow method originally developed by Boxer et al. [15] is not suitable in this case mainly due to the significant velocity growth in the rotor channels (from $171 \mathrm{~m} / \mathrm{s}$ to $236 \mathrm{~m} / \mathrm{s}$ ). Due to lack of a suitable design method the rotor was designed so that the blade angles match the predicted flow angles and the channel width between the blades is constant. The blading of the stage is presented in Figure 4.

The computational domain of the numerical task consisted of one nozzle channel and one rotor blade. The numerical model was consistent with the description in part 1.6. The total size of the mesh was 2.3 million nodes. The size of the nozzle mesh was 1.7 million nodes, the rotor domain consisted of 0.6 million nodes.

The distribution of the velocity and static pressure at $50 \%$ of the span are shown in Figure 5 and Figure 6 . The velocity distribution shows lack of flow separation in the rotor domain. This results in relatively high internal efficiency which is equal to $81.4 \%$. In the presented case the exit loss is equal to about $4 \%$. This loss can be reduced be using a diffuser, however, in a radial outflow turbine designing a large diffuser will significantly increase the ex-
Table 2: Design parameters of the centrifugal stage.

\begin{tabular}{lc}
\hline Total inlet pressure & $7 \mathrm{bar}(\mathrm{a})$ \\
\hline Total inlet temperature & $248^{\circ} \mathrm{C}$ \\
Total outlet pressure & $0.17 \mathrm{bar}(\mathrm{a})$ \\
Design mass flow rate & $1.57 \mathrm{~kg} / \mathrm{s}$ \\
Rotational speed & $20000 \mathrm{rpm}$ \\
\hline
\end{tabular}

ternal casing size which would be problematic from the point of view of mechanical design. A significant fraction of the overall loss is caused by the shocks in the rotor which are much stronger than in the nozzle (at least at the nominal point). The gap between the nozzle and rotor is also a source of loss. On one hand, the smaller the gap the smaller are the friction losses in the bladeless region but on the other hand the stronger is the rotor-stator interaction which has a negative influence on the efficiency. Finding the optimal radial gap size was not the subject of this paper and should be studied in future analysis.

The most important results obtained from CFD simulations are shown in Table 5. The resulting mass flow rate is only $0.13 \%$ different from designed one. This shows a very good agreement between methods of characteristics and CFD. The small difference is a result of the boundary layer which was not taken into account in MOC.

The designed shape of the nozzle is not optimal from the point of view of a centrifugal blade row because it produces the parallel and uniform flow instead of circumferentially uniform one. On the other hand, the MOC seems to be a good starting point since there is no dedicated design method in the literature. In future, the optimization methodology for a centripetal supersonic nozzle described by Pasquale et al. [16] will be adopted. Also, a dedicated rotor blade design method should be developed or, alternatively, a proper optimization method should be applied [17].

\section{The $200 \mathrm{~kW}$ radial turbine}

The centripetal turbine stages are widely used whenever a compact design is required, for example in the turbochargers. This type of stage is characterized by a good efficiency and can process relatively large enthalpy drops. In case of large particle fluids, like MDM, the pressure ratio can exceed 100. On the basis of the previous designs $[18,19]$ the dimensions and rotational speed have been adopted in order to meet the demands of the new power output, assuming that the flow angle at the nozzle outlet should be 
Table 3

\begin{tabular}{ccccccccccc}
\hline & $\mathrm{c}[\mathrm{m} / \mathrm{s}]$ & $\mathrm{w}[\mathrm{m} / \mathrm{s}]$ & $\alpha\left[^{\circ}\right]$ & $\beta\left[^{\circ}\right]$ & $\mathrm{M}[-]$ & $\mathrm{D}[\mathrm{mm}]$ & $\mathrm{l}[\mathrm{mm}]$ & $\mathrm{p}[\mathrm{bar}(\mathrm{a})]$ & $\mathrm{T}\left[{ }^{\circ} \mathrm{C}\right]$ & $\rho\left[\mathrm{kg} / \mathrm{m}^{3}\right]$ \\
\hline 0 & & & & & & & & 7 & 248 & 54.97 \\
1 & 320.6 & 171 & 12.8 & 24.5 & 2.46 & 150 & 36 & 0.22 & 210.7 & 1.31 \\
2 & 59.5 & 236.1 & 88.2 & 165.4 & 1.81 & 220 & 38 & 0.17 & 211.1 & 1.01 \\
\hline
\end{tabular}

Table 4: General characteristics of the stage.

\begin{tabular}{lc}
\hline Rotational speed & $20000 \mathrm{rpm}$ \\
Internal power & $76.4 \mathrm{~kW}$ \\
Internal efficiency & $81 \%$ \\
Degree of reaction & $7.2 \%$ \\
Number of nozzle channels & 12 \\
Number of rotor blades & 31 \\
Critical section of a single nozzle & $1.08 \mathrm{~mm}$ \\
channel & \\
\hline
\end{tabular}

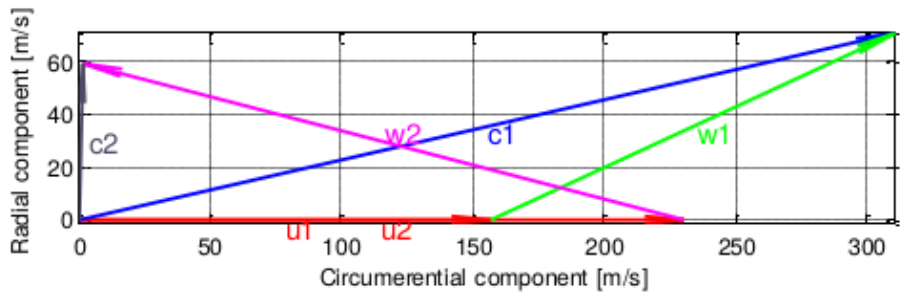

Figure 2: Velocity triangles of the centrifugal stage.

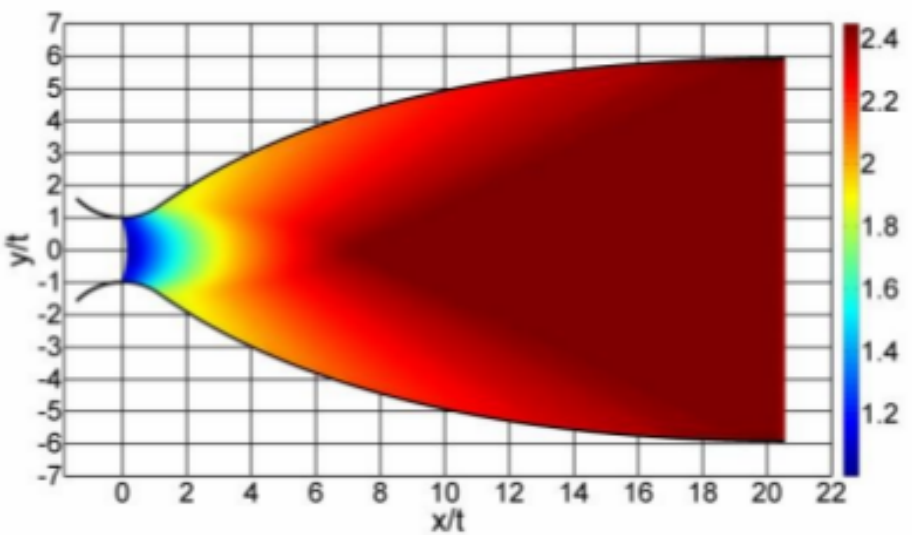

Figure 3: Distribution of the Mach number in the supersonic nozzle.

Table 5: The most important results obtained from CFD.

\begin{tabular}{ll}
\hline Mass flow rate & $1.568 \mathrm{~kg} / \mathrm{s}$ \\
Internal power & $78 \mathrm{~kW}$ \\
Internal efficiency & $81.4 \%$ \\
\hline
\end{tabular}




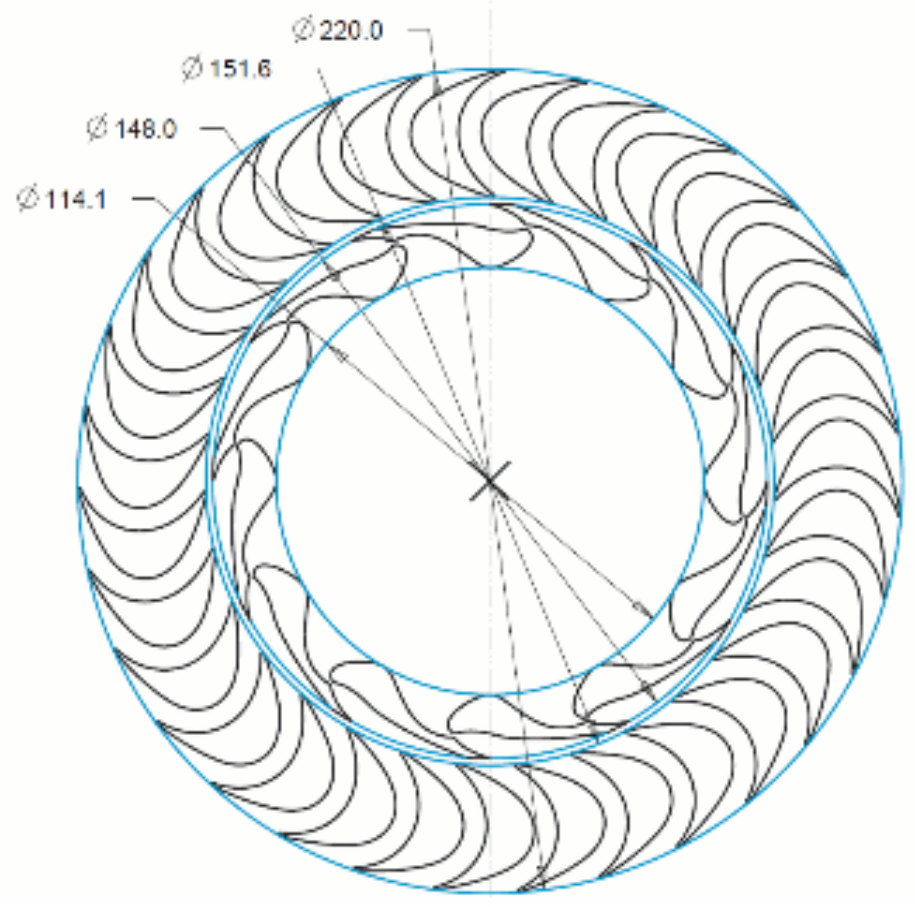

Figure 4: The blading of the centrifugal stage.
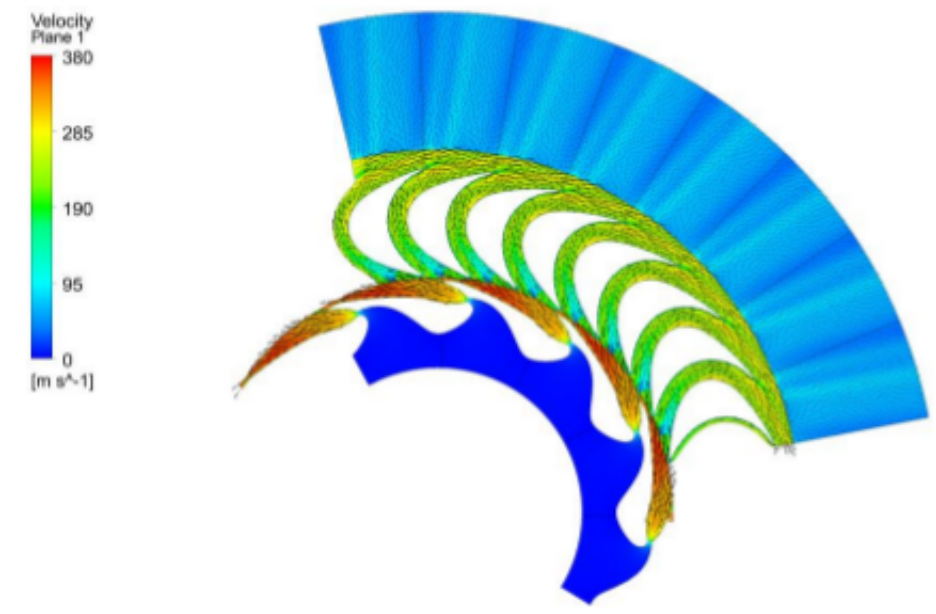

Figure 5: The distribution of the velocity at $50 \%$ of the span. 

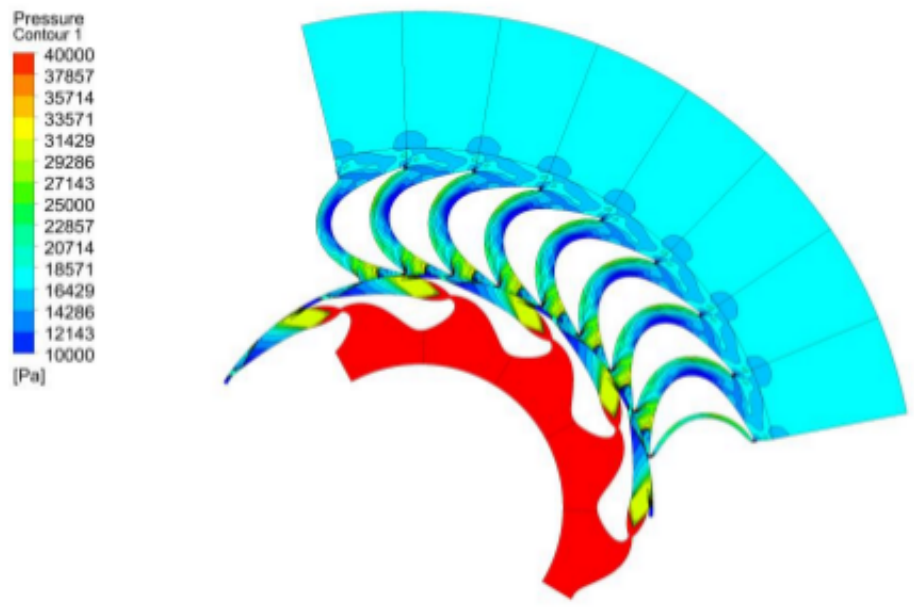

Figure 6: The distribution of the static pressure at $50 \%$ of the span.

greater than $10^{\circ}$. Additionally, a long blade has been imposed at the outlet in order to minimize the outflow loss. A classic reaction stage kinematics has been assumed (degree of reaction equal to $50 \%$ ). The set of the design parameters for the stage has been given in Table 6 . The main dimensions of the stage have been shown in Figure 7 while the velocity triangles have been displayed in Figure 8.

The stage geometry was produced by means of the methods described in the part 1.5. Due to a high value of the Mach number in the stator a convergent-divergent nozzle shape was necessary. Analogeously as in case of the centrifugal turbine, the method of characteristics for designing a flat nozzle was applied. The obtained nozzle shape has been presented in Figure 9. The geometry of the rotor blades has been created in Ansys BladeGen software.

It is assumed that the impeller is shrouded. This solution allows one not only to increase the efficiency of the stage but also to reduce the axial thrust exerted at the rotor. Figure 10 shows an exemplary dependence of a centripetal stage efficiency with respect to the tip clearance size. The rotor shrouding gives a benefit of efficiency of about 3 to 5 percentage points in the range of practical clearance sizes. The main disadvantage of a shrouded rotor is connected with the worse structural properties than in case of the unshroaded impeller. Thus, structural analysis is necessary because the peripheral speed is significant and equal to $240 \mathrm{~m} / \mathrm{s}$.

The hexahedral meshes prepared for the numerical simulations was equal to about 350 thousand nodes for every domain (single stator channel and single rotor channel). The results obtained from numerical simulations have been presented in Figures from 11 to 17 and in Table 7.

The internal efficiency of the stage obtained from simulations is equal $86.6 \%$. This is a very good result tak- ing into account a large pressure ratio processed by the turbine (about 70) and significant Mach number at the stator outflow (average value about 1.9). Nevertheless, a flow separation is visible in the rotor domain (Figure 16) which should be in future designs improved by means of optimization. One of the possible optimization direction would lead through changing the distribution of the $\beta^{\star}$ angle in the rotor and the meridional shape.

The performed simulations neglect the leakage over the rotor shrouding which in reality would introduce additional loss and reduce the efficiency. The effect of this clearance will be taken into account in future studies in order to estimate the machine performance and to obtain the optimal size of the gap.

The presented results were performed for the nominal point but from the point of view of the real system also the off-design performance should be investigated. Because of the large value of the Mach number the part-load efficiency can be poor.

\section{The $500 \mathrm{~kW}$ radial turbine}

Since the design parameters, except the power capacity, are exactly the same the turbine geometry presented in the previous section can be used. In order to obtain the appropriate mass flow rate through the machine the shape of the blade rows must be properly rescaled. At the same time, to keep the fixed value of the peripheral velocity, the rotational speed has to be changed. It is expected that the losses in the whole stage will be only slightly changed because the Reynolds number influence will be small. Its value in the stator will rise from 5 million to about 8 mil- 
Table 6: Design parameters for the centripetal stage.

\begin{tabular}{ll}
\hline Total inlet pressure & $12 \mathrm{bar}(\mathrm{a})$ \\
Total inlet temperature & $535.5 \mathrm{~K}$ \\
Total outlet pressure & $0.17 \mathrm{bar}(\mathrm{a})$ \\
Mass flow rate & $3.5 \mathrm{~kg} / \mathrm{s}$ \\
Rotational speed & $13500 \mathrm{rpm}$ \\
\hline
\end{tabular}

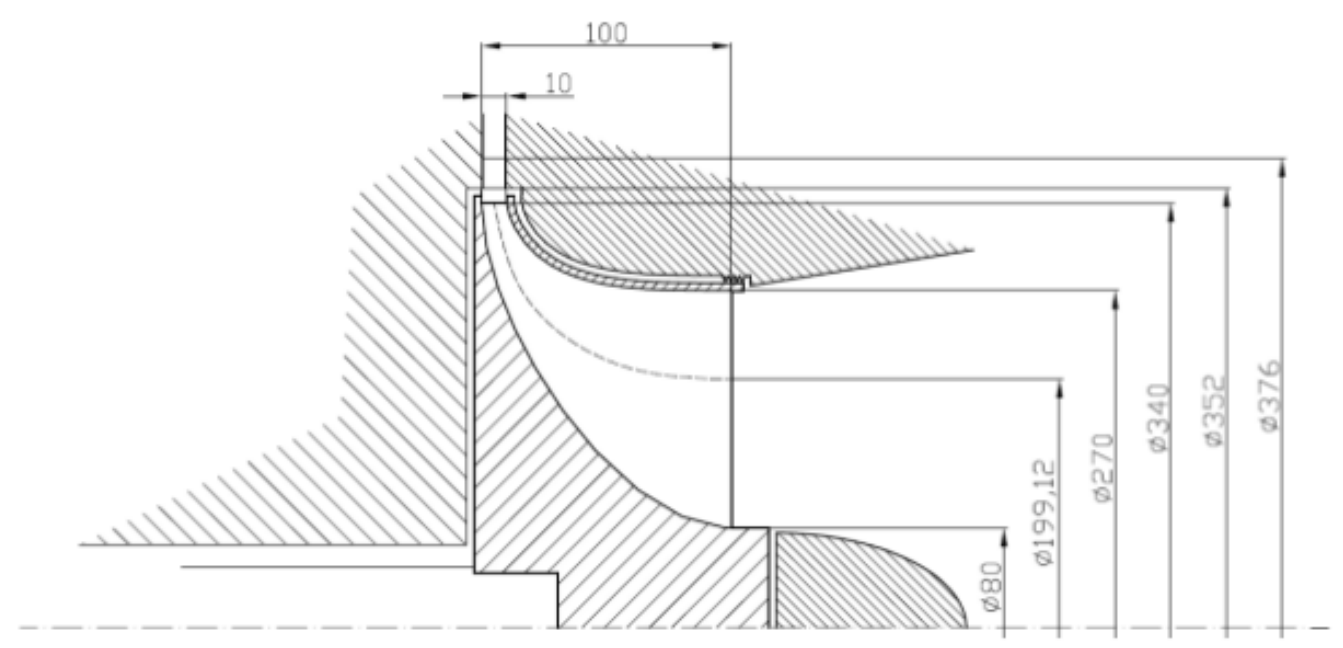

Figure 7: Main dimensions of the centripetal turbine stage.

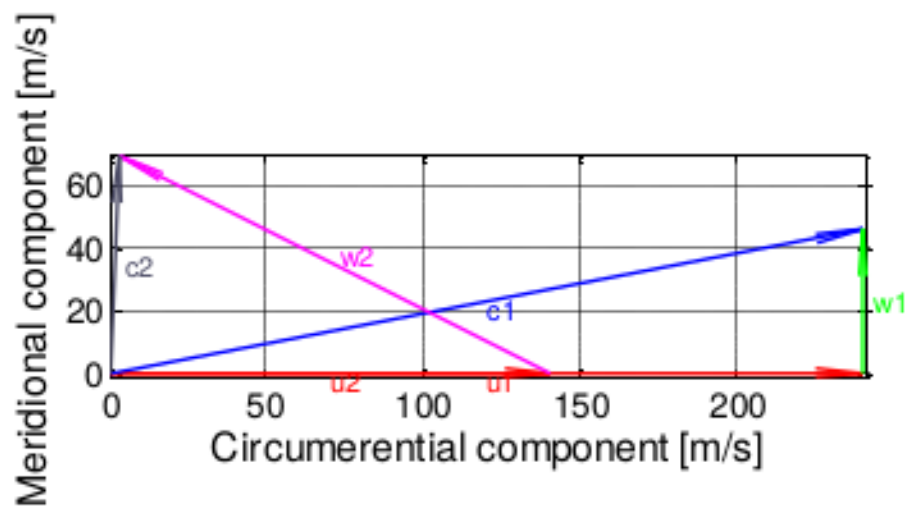

Figure 8: Kinematics of the centripetal stage.

Table 7: Results of numerical simulations of the centripetal stage.

\begin{tabular}{lccccccc}
\hline$\dot{m}, \mathrm{~kg} / \mathrm{s}$ & $P_{0}^{\star}, \mathrm{kPa}$ & $T_{0}^{\star}, \mathrm{K}$ & $P_{1}, \mathrm{kPa}$ & $T_{1}, \mathrm{~K}$ & $P_{2}, \mathrm{kPa}$ & $T_{2}, \mathrm{~K}$ & $c_{1}, \mathrm{~m} / \mathrm{s}$ \\
\hline 3.497 & 1200 & 553.5 & 129 & 518.9 & 17 & 500.6 & 248.7 \\
& & & & & & & \\
$c_{2}, \mathrm{~m} / \mathrm{s}$ & $w_{1}, \mathrm{~m} / \mathrm{s}$ & $w_{2}, \mathrm{~m} / \mathrm{s}$ & $\alpha_{2}, \mathrm{deg}$ & $\mathrm{P}, \mathrm{kW}$ & $\eta_{i}, \%$ & & \\
\hline 80.8 & 52.2 & 155 & 92.2 & 211 & 86.6 & & \\
\hline
\end{tabular}




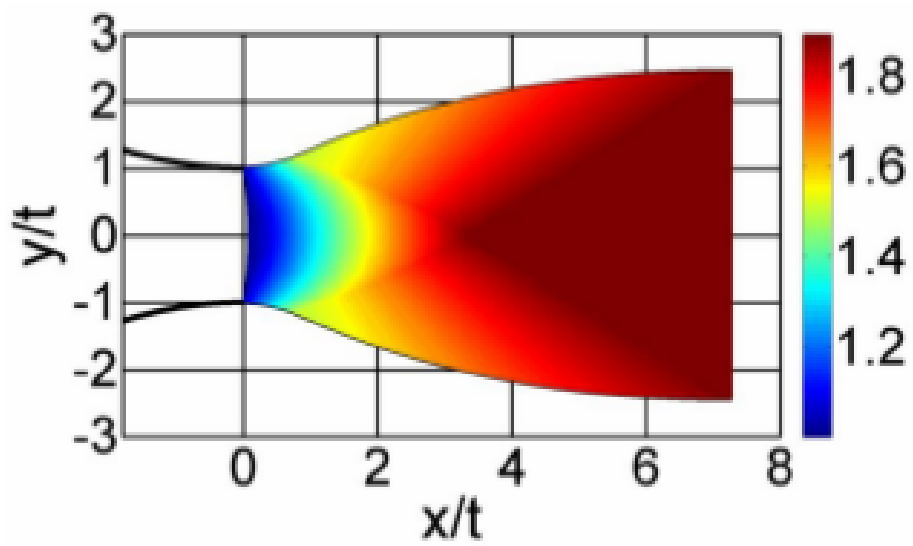

Figure 9: The distribution of the Mach number in the designed nozzle.

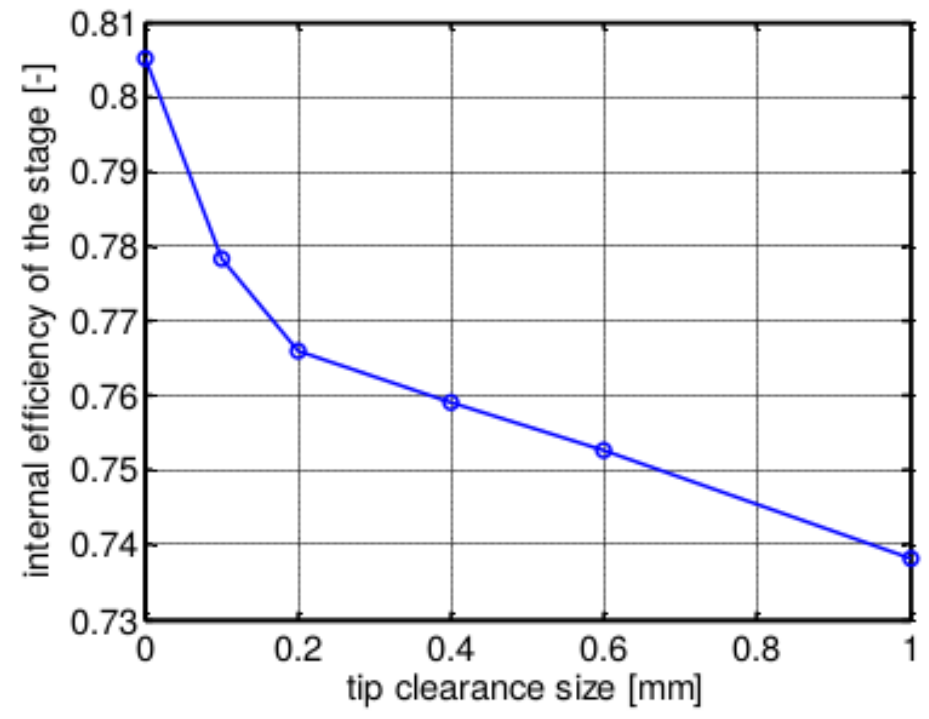

Figure 10: Internal efficiency of an examplary centripetal stage with respect to the tip clearance size.

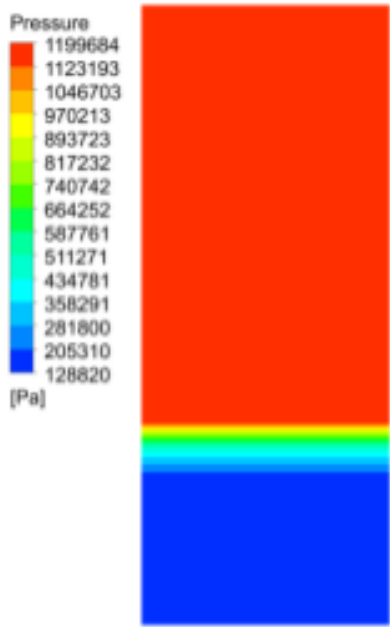

Figure 11: Static pressure in the nozzle averaged along the circumference. 


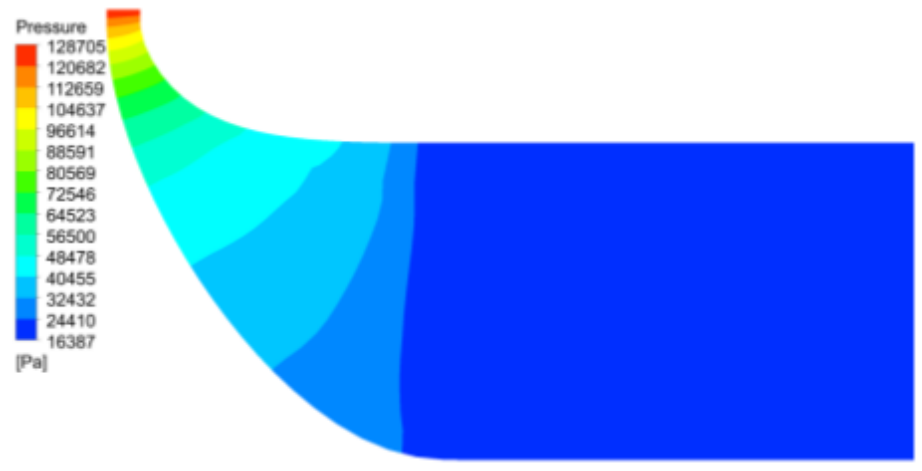

Figure 12: Static pressure in the rotor averaged along the circumference.

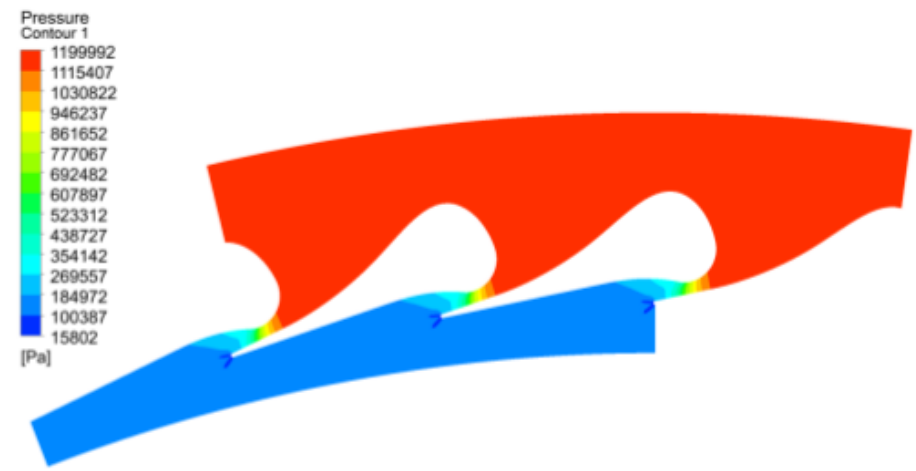

Figure 13: Static pressure distribution in the nozzle at $50 \%$ of the normalized span.

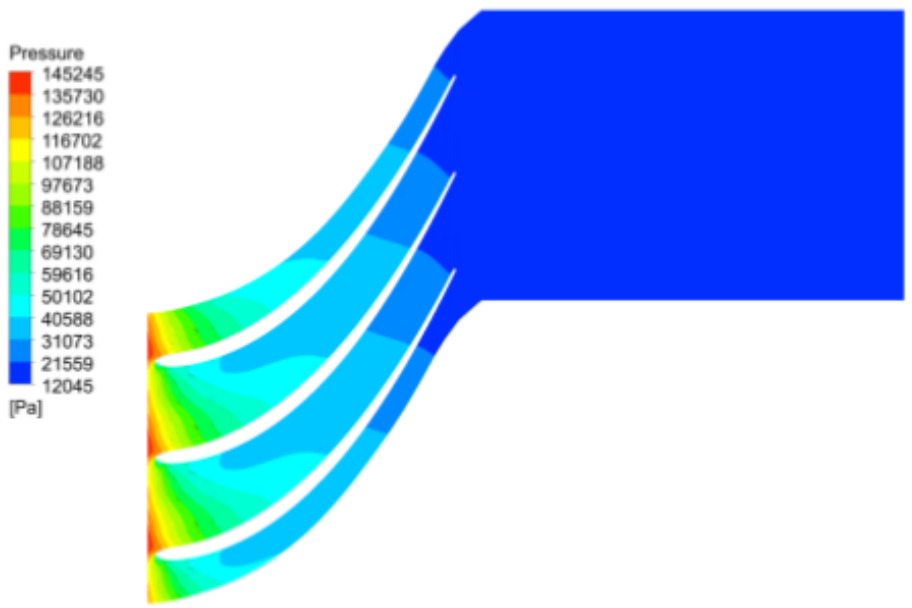

Figure 14: Static pressure distribution in the rotor at $50 \%$ of the normalized span. 


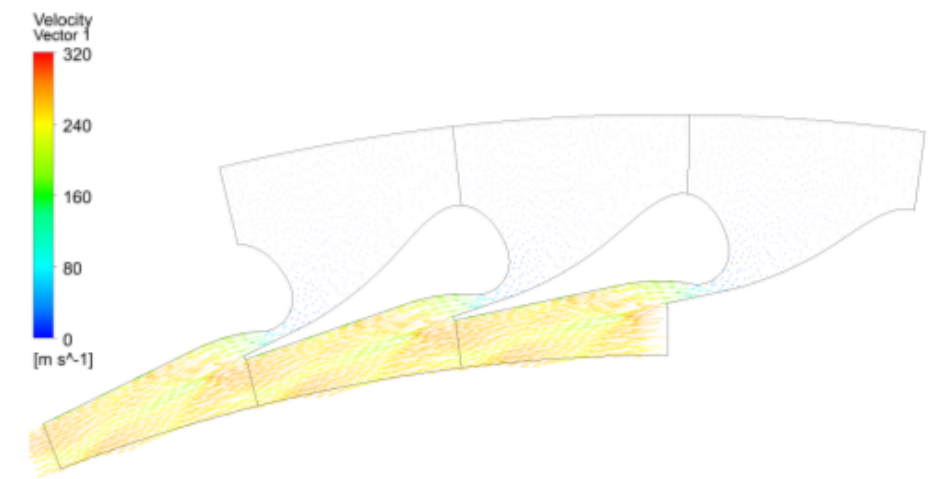

Figure 15: Velocity vectors in the nozzle at $50 \%$ of the normalized span.

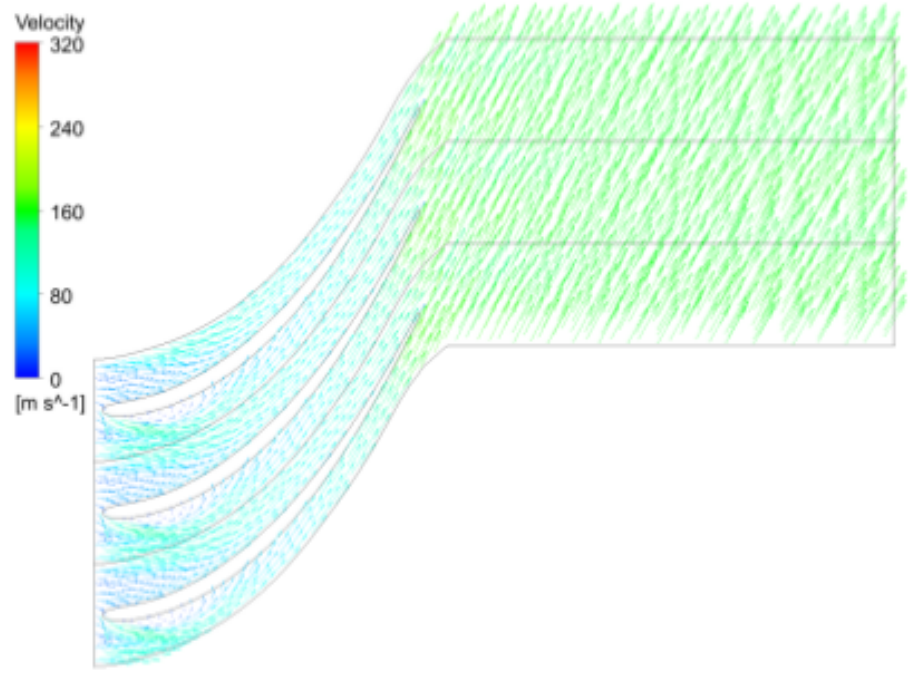

Figure 16: Velocity vectors in the rotor at $50 \%$ of the normalized span.

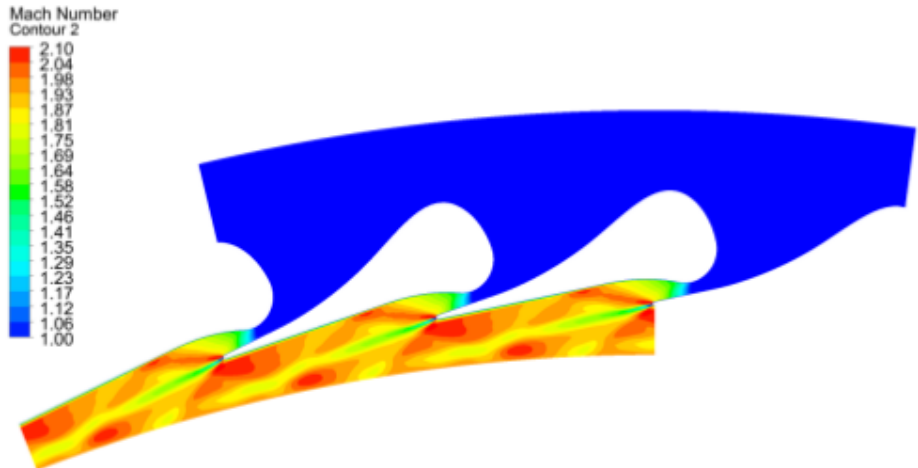

Figure 17: Mach number in the stator at $50 \%$ of the normalized span. 


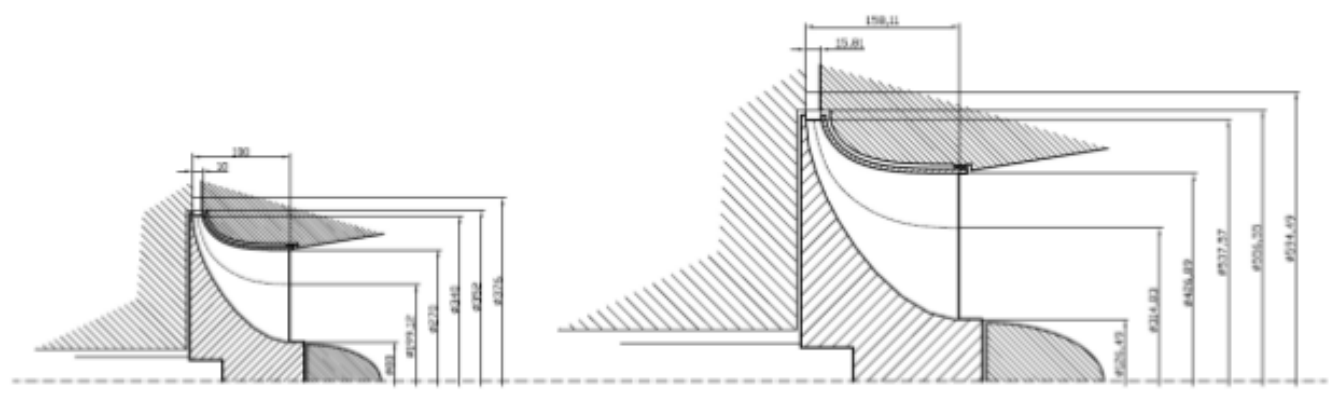

Figure 18: The comparison of the main dimensions of the $200 \mathrm{~kW}$ and $500 \mathrm{~kW}$ stages.

Table 8: Detailed results of 1D computations for $500 \mathrm{~kW}$ axial turbine.

\begin{tabular}{lcccccccccc}
\hline & 1 & 2 & 3 & 4 & 5 & 6 & 7 & 8 & 9 & 10 \\
\hline $\begin{array}{l}\text { Internal } \\
\text { power [kW] }\end{array}$ & 34.54 & 41.49 & 47.73 & 54.11 & 60.71 & 68.08 & 74.38 & 78.4 & 80.52 & 81.09 \\
$\begin{array}{l}\text { Internal } \\
\text { efficiency [\%] }\end{array}$ & 80 & 82 & 84.3 & 85.7 & 86.5 & 87.7 & 89.2 & 90.3 & 90.9 & 91.2 \\
$\begin{array}{l}\text { Degree of re- } \\
\text { action [\%] }\end{array}$ & 5 & 7 & 10 & 14 & 18 & 22 & 29 & 37 & 47 & 60 \\
$\begin{array}{l}\text { Number of } \\
\text { stator blades }\end{array}$ & 29 & 31 & 34 & 40 & 47 & 56 & 54 & 44 & 35 & 30 \\
$\begin{array}{l}\text { [-] } \\
\text { Number of ro- } \\
\text { tor blades [-] }\end{array}$ & 102 & 115 & 127 & 139 & 150 & 151 & 127 & 85 & 53 & 34 \\
\hline
\end{tabular}
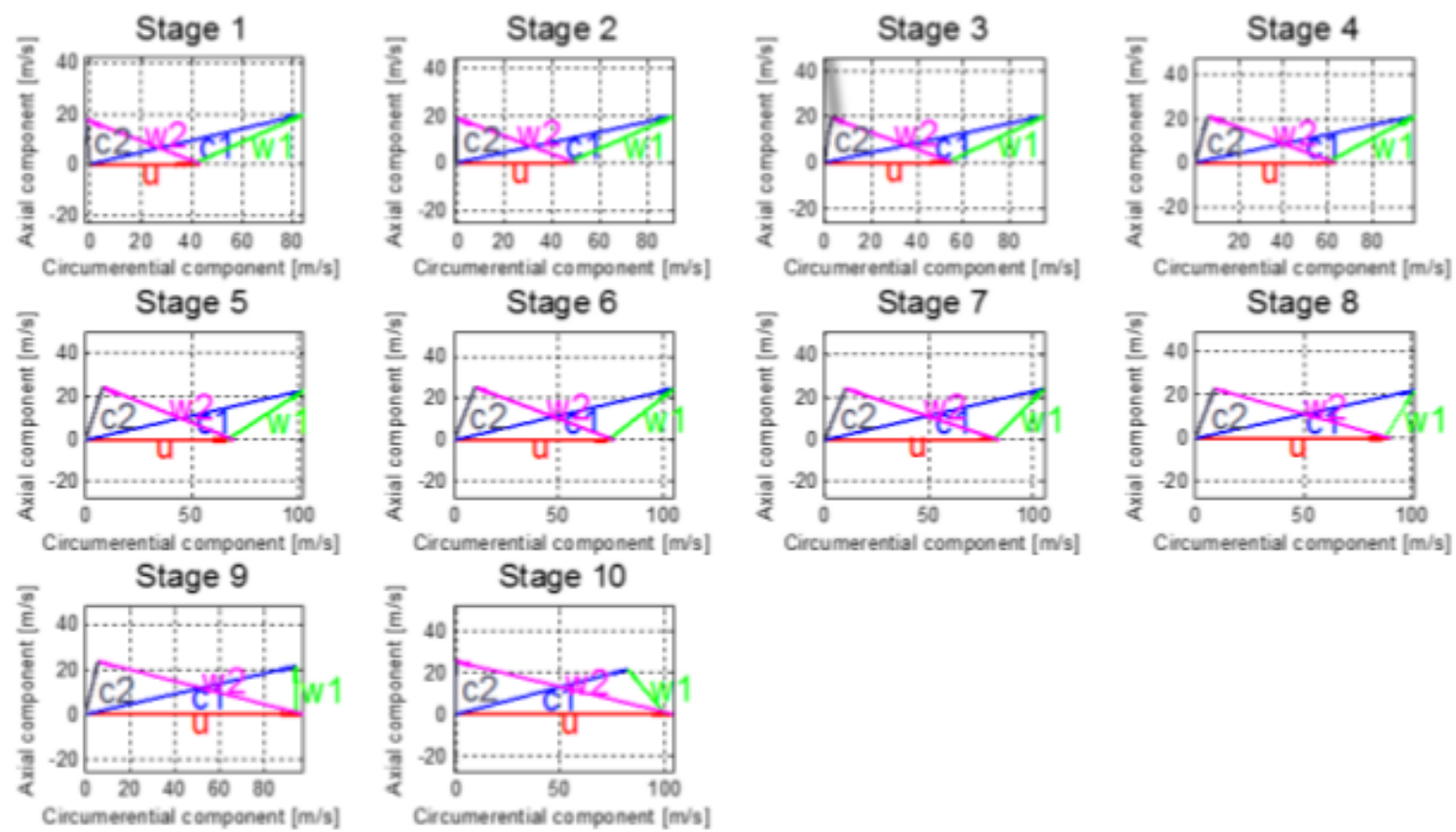

Figure 19: Velocity triangles of the $500 \mathrm{~kW}$ axial turbine. 


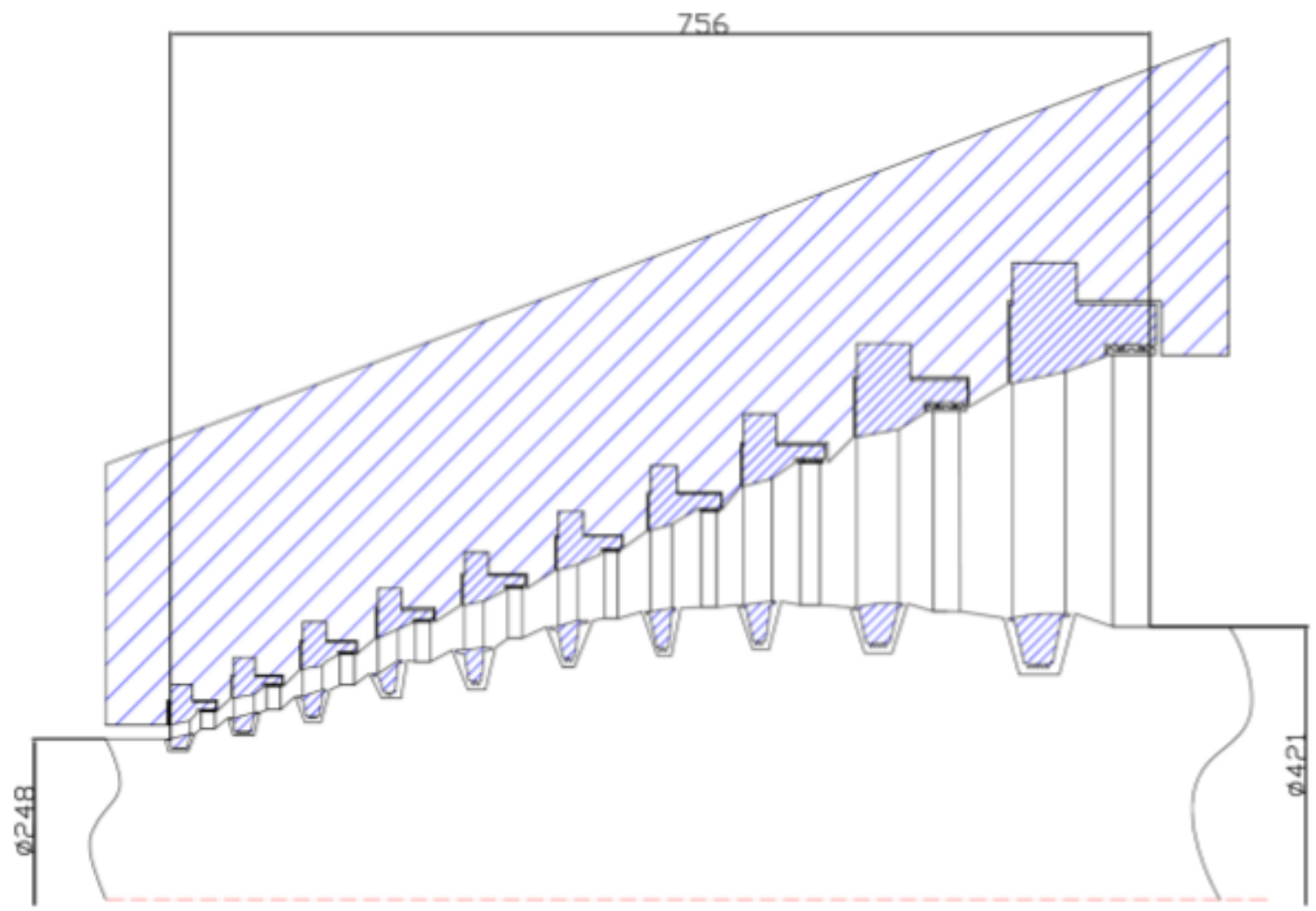

Figure 20: Meridional view of the $500 \mathrm{~kW}$ axial turbine.

Table 9: Detailed results of 1D computations for $1 \mathrm{MW}$ axial turbine.

\begin{tabular}{|c|c|c|c|c|c|c|c|c|c|c|}
\hline & 1 & 2 & 3 & 4 & 5 & 6 & 7 & 8 & 9 & 10 \\
\hline $\begin{array}{l}\text { Internal } \\
\text { power [kW] }\end{array}$ & 70.31 & 74.29 & 78.19 & 85.2 & 95.06 & 109.81 & 128.26 & 148.83 & 171.07 & 194.05 \\
\hline $\begin{array}{l}\text { Internal } \\
\text { efficiency [\%] }\end{array}$ & 84 & 85.4 & 86.4 & 86.5 & 85.7 & 85.9 & 87 & 88.5 & 89.6 & 89.4 \\
\hline $\begin{array}{l}\text { Degree of re- } \\
\text { action [\%] }\end{array}$ & 5 & 7 & 10 & 14 & 18 & 22 & 29 & 37 & 47 & 60 \\
\hline $\begin{array}{l}\text { Number of } \\
\text { stator blades } \\
{[-]}\end{array}$ & 35 & 37 & 37 & 42 & 52 & 63 & 64 & 53 & 44 & 39 \\
\hline $\begin{array}{l}\text { Number of ro- } \\
\text { tor blades [-] }\end{array}$ & 111 & 114 & 122 & 135 & 151 & 161 & 145 & 104 & 68 & 48 \\
\hline
\end{tabular}



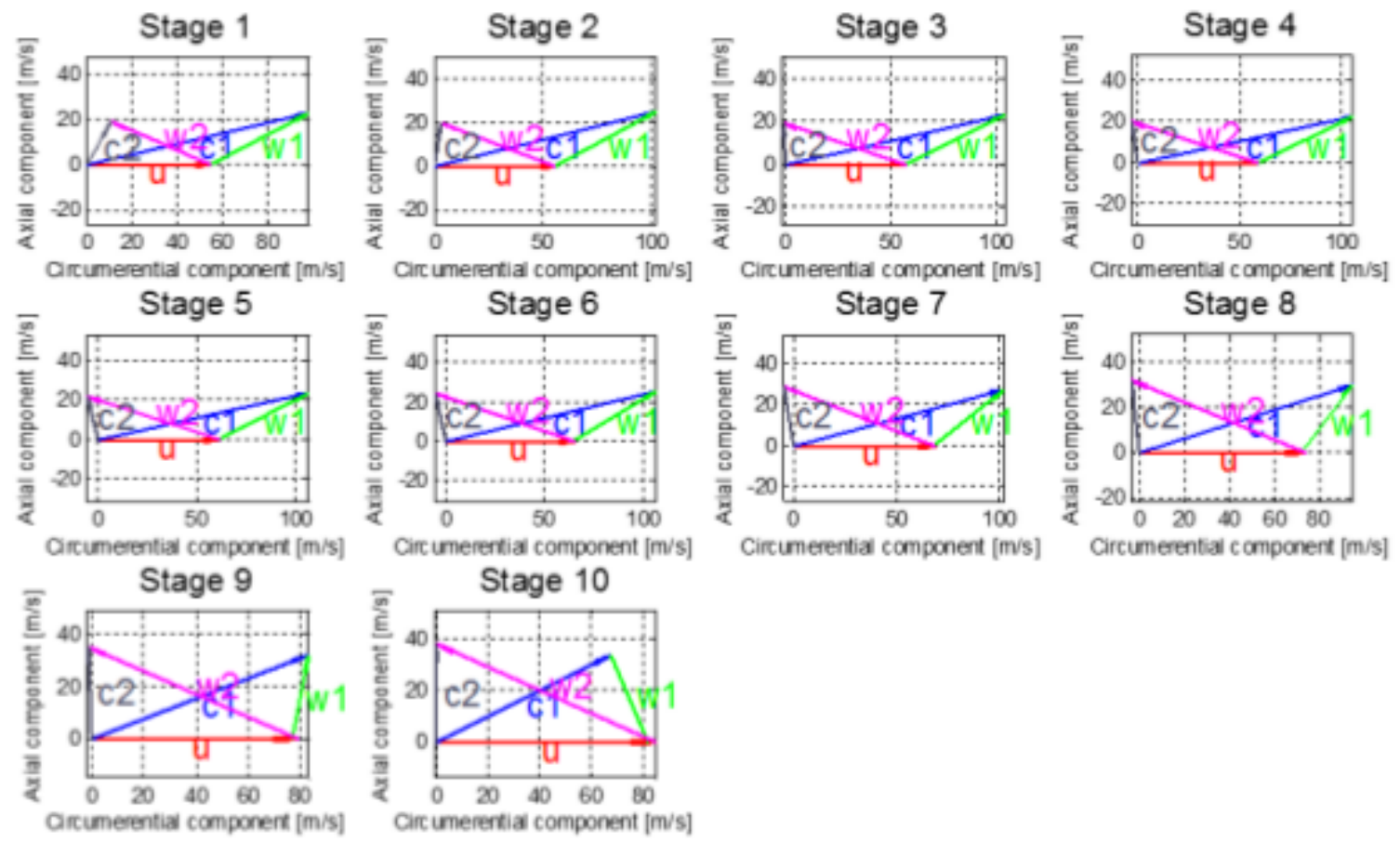

Figure 21: Velocity triangles of the $1 \mathrm{MW}$ axial turbine.

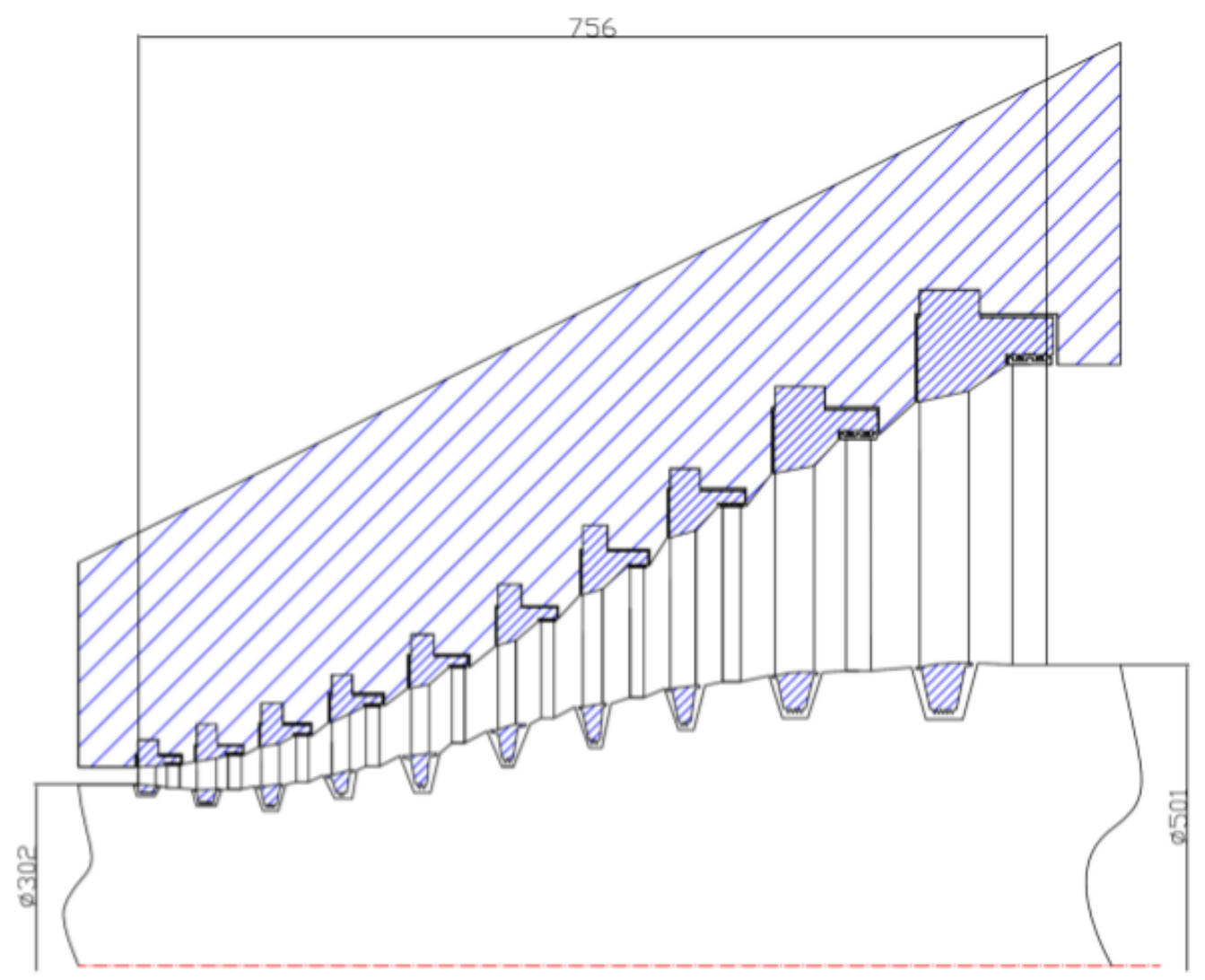

Figure 22: Meridional view of the $1 \mathrm{MW}$ axial turbine. 
lion and in the rotor from 3 million to 4.8 million. The loss correlations predict that the internal efficiency of the stage will be changed by less than 0.5 percentage points assuming that the relative roughness of the blade surface is maintained. Additionally, the losses could be reduced if the tip clearance is taken into account. In order to change the power output of the stage from $200 \mathrm{~kW}$ to $500 \mathrm{~kW}$ the scale factor must be equal to 1.581 which is the square root from the ratio of those two values. Thus, the rotational speed will be reduced from $13500 \mathrm{rpm}$ to about $8500 \mathrm{rpm}$. The comparison of the original stage and the rescaled one has been presented in Figure 18.

\section{The $500 \mathrm{~kW}$ and $1 \mathrm{MW}$ axial stages}

The purpose of this part of the paper is to project the performance of two axial turbines $(500 \mathrm{~kW}$ and $1000 \mathrm{~kW})$, that were designed for the same input parameters except the mass flow rate, i.e. inlet pressure, temperature and outlet pressure. The stage design procedure was based on $1 \mathrm{D}$ computational matlab code which is consistent with the description given in the part 1.4. The ORC turbine design process, and more specifically the flow path design process, was based on the distribution of enthalpy drops and degrees of reaction in the particular stages. The general sequence of this process includes:

1. Turbine basic specifications, i.e. rotational speed, number of stages, pressures, temperatures and some assumed distributions of enthalpy drops and degrees of reaction.

2. Determination of the optimum flow path. The optimization algorithm calculates the sets of geometrical parameters seeking for the maximum of the objective function which is the internal efficiency of the turbine.

On the contrary to the highly loaded turbines described in previous sections, the machines described here have many stages, low Mach numbers and efficiencies above 90\%.

\subsection{The $500 \mathrm{~kW}$ turbine}

The mass flow rate in this case is $9.78 \mathrm{~kg} / \mathrm{s}$ and the rotational speed equals to $3000 \mathrm{rpm}$, the number of stages is 10. The computed value of the efficiency is $91 \%$. Table 8 presents the detailed results of the calculations while Figures 19 and 20 show the velocity triangles of the stages and the main dimensions of the whole group.

\subsection{The $1 \mathrm{MW}$ turbine}

The design mass flow rate for this case was increased to $19.56 \mathrm{~kg} / \mathrm{s}$ while the rotational speed was kept at $3000 \mathrm{rpm}$. The internal efficiency is equal to $92 \%$ so it is 1 percentage point higher than in the previous case. The detailed 1D calculation results for every stage have been presented in Table 9. Figures 21 and 22 present the kinematics of the stages and main dimensions of the whole turbine.

\section{Conclusions}

The presented turbines were designed according to the principle that in case of the small power turbines the most important feature is the compact design and cheap manufacturing. The resulting efficiency should be as high as possible but it is not the primary issue. The described highly loaded stages achieve satisfying efficiency values despite of high Mach numbers in the stator. Along with increasing power output the design complexity can be increased. The multistage axial turbines described in the paper have much better efficiencies but their designs are much more sophisticated. They require significantly bigger manufacturing effort.

The next step will be the detailed analysis of the clearance flow in the stages. Also, turbines optimization will be performed which will be preceded by the sensitivity analysis in order to determine which of the geometrical parameters have the biggest influence on the efficiency.

Acknowledgement: The authors appreciate the financial support of the National Centre for Research and Development project "Developing integrated technologies of fuel and energy production from biomass, agricultural wastes and other resources".

\section{Nomenclature}

$c$ - velocity in stationary reference frame $[\mathrm{m} / \mathrm{s}]$

$w$ - velocity in relative reference frame $[\mathrm{m} / \mathrm{s}]$

$\alpha$ - velocity flow angle in stationary reference frame $\left[^{\circ}\right]$

$\beta$ - velocity flow angle in relative reference frame $\left[^{\circ}\right]$

$M$ - Mach number [-]

$D$ - mean diameter of a stage $[\mathrm{mm}]$

$l$ - length of a blade [mm]

$p$ - pressure [bar] or $[\mathrm{kPa}]$

$T$ - temperature $\left[{ }^{\circ} \mathrm{C}\right]$ or $\left[{ }^{\circ} \mathrm{K}\right]$

$\rho$ - density $\left[\mathrm{kg} / \mathrm{m}^{3}\right]$ 
Indices:

0 - stage inlet

1 - rotor inlet

2 - rotor outlet

\section{References}

[1] Turunen-Saaresti T., Uusitalo A., Honkatukia J., Larjola J., Effects of Turbine Efficiency to Small-Scale ORC Process Electricity Production and Profitability, in: First Int. Semin. ORC Power Syst. ORC 2011, Delft, 2011.

[2] Klonowicz P., Heberle F., Preißinger M., Brüggemann D., Significance of loss correlations in performance prediction of small scale, highly loaded turbine stages working in Organic Rankine Cycles, Energy, 2014, 72, 322-330.

[3] Craig H.R.M., Cox H.J.A., Performance Estimation of Axial Flow Turbines, Proc. Inst. Mech. Eng. 1970, 185, 407-424.

[4] Guardone A., Spinelli A., Dossena V., Vandecauter V., Influence of Molecular Complexity on Nozzle Design for an Organic Vapor Wind Tunnel, in: First Int. Semin. ORC Power Syst. ORC 2011, 2011.

[5] Colonna P., Gallo M., Casati E., Mathijssen T., Flexible Asymmetric Shock Tube (FAST). Status and first experiences, in: 2nd Int. Semin. ORC Power Syst. ASME ORC 2013, Rotterdam, 2013.

[6] Spinelli A., Dossena V., Gaetani P., Start-up of a Test Rig for Organic Vapors, in: 2nd Int. Semin. ORC Power Syst. ASME ORC 2013, 2013.

[7] Zucrow M.J., Hoffman J.D., Gas Dynamics Volume I and II, Wiley, New York, 1976.

[8] Papierski A., Wielokryterialna i wielopoziomowa optymalizacja kształtu półotwartych wirników pomp o niskich wyróżnikach szybkobieżności, Politechnika Łódzka, Łódź, 2010.

[9] Harinck J., Pasquale D., Pecnik R., Colonna P., ThreeDimensional RANS Simulation of a High-Speed Organic Rankine Cycle Turbine, in: First Int. Semin. ORC Power Syst. ORC 2011, Delft, 2011.
[10] Klonowicz P., D. Brüggemann, 2D Unsteady RANS Simulations of an Organic Vapor Partial Admission Turbine, in: ASME ORC 2013, 2nd Int. Semin. ORC Power Syst., Rotterdam, 2013.

[11] Klonowicz P., Sobczak K., Fijatkowski T., Analysis of Kinematics for a Single-Stage ORC Impulse Turbine, in: 10th Int. Symp. Compress. Turbine Flow Syst. - Theory Appl. Areas Symkom 2011, Lodz, 2011.

[12] Klonowicz P., Borsukiewicz-Gozdur A., Hanausek P., Kryłtowicz W., Brüggemann D., Design and performance measurements of an organic vapour turbine, Appl. Therm. Eng. 2014, 63, 297-303.

[13] Lemmon E.W., Huber M.L., McLinden M.O., NIST Standard Reference Database 23: Reference Fluid Thermodynamic and Transport Properties-REFPROP, Version 9.1, National Institute of Standards and Technology, Standard Reference Data Program, Gaithersburg, 2013.

[14] Cho S., Ahn K., Lee Y., Performance Characteristics of a Partially Admitted Small-Scale Mixed-Type Turbine, Int. J. Turbo JetEngines., 2011, 28, 299-307.

[15] Boxer E., Sterrett J.R., Wlodarski J., Application of supersonic vortex-flow theory to the design of supersonic impulse compressor- or turbine-blade sections, NACA RM L52B06. 1952.

[16] Pasquale D., Ghidoni A., Rebay S., Shape Optimization of an ORC Radial Turbine Nozzle, in: First Int. Semin. ORC Power Syst. ORC 2011, Delft, 2011.

[17] Kozanecki Z., Kozanecka D., Klonowicz P., Łagodziński J., Gizelska M., Tkacz E., et al., Bezolejowe maszyny przeptywowe matej mocy, Wydawnicta Instytutu Maszyn Przepływowych PAN, Gdańsk, 2014.

[18] Rusanov A,. Lampart P., Szymaniak M., Bykuć S., Koronowicz J., Szymaniak A., Zadanie Badawcze Nr 4 „Opracowanie zintegrowanych technologii wytwarzania paliw i energii z biomasy, odpadów rolniczych i innych.", Opracowanie układu przepływowego jednostopniowej turbiny promieniowo-osiowej ORC 100 kw, IMP PAN, Gdańsk, 2013.

[19] Rusanov A,. Lampart P., Szymaniak M., Bykuć S., Zadanie Badawcze Nr 4 „Opracowanie zintegrowanych technologii wytwarzania paliw i energii z biomasy, odpadów rolniczych i innych.", Opracowanie uktadu przepływowego dwustopniowej (symetrycznej) turbiny promieniowo-osiowej ORC $100 \mathrm{~kW}$, IMP PAN, Gdańsk, 2013. 